\title{
ANAPHYLACTIC REACTION CAUSED BY INTRAMUSCULAR INJECTION OF LYOPHILIZED ALPHA-CHYMOTRYPSIN*
}

\author{
BY \\ PETER G. WATSON \\ Department of Clinical Ophthalmology, Institute of Ophthalmology, London
}

IN August, 1952, Innerfield and his colleagues (Innerfield, Schwarz, and Angrist, 1952; Innerfield and Schwarz, 1953) reported that intravenous crystalline trypsin showed a marked fibrinolytic, thrombolytic, and anticoagulant effect on extravasated blood remote from the site of injection. This led Hopen $(1953,1954)$ and Hopen and Campagna (1954) to use this substance, which was to be found equally effective given intramuscularly in sesame oil, in a variety of acute inflammatory and haemorrhagic ocular disturbances. They came to the conclusion that extra-ocular haemorrhages and hyphaemata cleared more rapidly on treatment, but that the results in vitreous haemorrhage were equivocal. Chandler and Rosenthal (1958) repeated these observations with rabbits, and found that trypsin had no effect on blood in the vitreous in rabbit eyes. Reports then appeared (Taylor, Overman, and Wright, 1954; Peck 1954) that trypsin had some marked toxic reactions, and it was largely replaced by the less toxic alpha-chymotrypsin. Several reports followed (Montauffier, de la Bernardie, and Camo, 1957; Mercier and Jezegabel, 1960; Perdriel, 1960) suggesting its value in vitreous haemorrhage and reporting an action similar to that of trypsin in intra-ocular haemorrhage.

Chymotrypsin is a proteolytic enzyme probably identical with pancreatic rennin. It acts by breaking the peptide linkages within the protein molecule at the carboxyl groups of tyrosine and phenylalanine, whereas trypsin breaks the peptide linkages at the carboxyl groups of arginine and lysine. The toxicology of trypsin and chymotrypsin was studied in animals by Hendley, Robbins, Dertinger, Clements, and Ercoli (1956). Chymotrypsin was found to be less toxic than trypsin but was nevertheless capable of producing irreversible shock with respiratory and cardiac arrest when given in large doses. It was also found to be a potent anticoagulant.

Anaphylaxis, first described by Portier and Richet (1902), is a condition in which systemic collapse is induced by the injection of a foreign substance, usually protein, to which the individual has been sensitized by a previous injection of the same substance. The collapse is thought to be caused by the sudden release of heparin and histamine from the mitochrondria of the mast cells which are found mainly in the skin and liver. In man the release of these substances causes collapse, fall in blood pressure and associated tachycardia, dyspnoea of the asthmatic type, suffusion of the face, urticaria, and oedema of the extremities (Wolstenholme and O'Connor, 1956).

* Received for publication April 18, 1963. 


\section{Case Report}

An accountant aged 41 was first seen in October, 1955, with a vitreous haemorrhage in the right eye. When this cleared the retina showed an area of exudation associated with some new vessel formation. The vessels leading to this area were sheathed and partly obliterated and there was some early organization of the vitreous overlying the area. A diagnosis of Eales's disease was made and, as the Mantoux reaction was strongly positive at $1 / 10,000$, a course of para-amino-salicylic acid (P.A.S.) and isonicotinic acid hydrazide (I.N.A.H.) was given. The condition improved considerably over the next 4 months but the patient then had a further haemorrhage; 5 weeks later he developed a generalized eczematous dermatitis and the drugs were stopped.

During the next 4 months he had recurrent haemorrhages and the visual acuity diminished from 6/12 to counting fingers at one metre. He was therefore admitted to hospital for a course of intramuscular trypsin. He had no ill-effects from the injection but the ocular condition was not in any way altered.

In 1958 he presented with a vitreous haemorrhage in the left eye. This eye had previously been unaffected but now showed the same changes as those seen in the right eye 2 years before. He was admitted to hospital and given a full 6-month course of streptomycin and I.N.A.H., subconjunctival hydrocortisone, and systemic prednisolone $5 \mathrm{mg}$. three times a day. In spite of this treatment the condition gradually progressed with organization of the vitreous and retinitis proliferans. He retained 6/6 vision until 1961, when there was a sudden and rapid increase in the organization of the vitreous not apparently associated with further bleeding. The dosage of prednisolone was increased to $60 \mathrm{mg}$. per day without improvement, and a continuous intravenous infusion of hydrocortisone $300 \mathrm{mg}$. daily was given for 5 days. After this, betamethasone $6 \mathrm{mg}$. per day was given and this dose was gradually reduced to $4 \mathrm{mg}$. per day. The visible area of fibrosis shrank considerably at the start of the intravenous therapy but this improvement was not maintained.

Because of the apparent failure of this treatment the patient was given a 14-day course of intramuscular lyophilized alpha-chymotrypsin, one ampoule three times a day, in addition to the betamethasone. A subjective and objective improvement occurred during this therapy; but the condition regressed as soon as it was stopped, and it was decided to give a further course starting 7 days later.

The first dose of this course was given deep into the buttock. No blood was seen on withdrawal of the plunger and none was found on the needle after it was removed. About one minute later the patient began to feel unwell, complaining that his mouth felt swollen, and 2 minutes later, whilst trying to sit on a bed-pan, he collapsed and became unconscious. His pulse was impalpable at the wrist but was counted at 160 over the heart. There were no heart murmurs. The blood pressure was unrecordable. His face was very flushed but there was no cyanosis or generalized urticaria. The most distressing feature was the breathlessness and the severe bronchospasm, but at no time was there apnoea. The limbs were ataxic.

He was at once given $1 \mathrm{ml}$. adrenaline 1/1,000. He immediately regained consciousness and became very restless, throwing off the mask through which oxygen was being administered. However, as the bronchospasm persisted, intravenous aminophylline was prepared. The patient had been given only $10 \mathrm{mg}$. of this, very slowly, when it became apparent that the bronchospasm was worsening. The injection was stopped and another $1 \mathrm{ml}$. of adrenalin 1/1,000 was given with an immediate response, so that he was able to talk within 15 seconds. He then vomited a small amount of yellow fluid and simultaneously his blood pressure rose to $120 / 80$, just below his normal level. The only abnormal physical signs at this stage were numerous high-pitched rhonchi all over the chest with rales at both bases, and a generalized blotchy erythema, both of which persisted for about 12 hours and gradually disappeared without further medication. Recovery was uneventful except that the blood pressure fell to $100 / 60$ for about 15 minutes, 9 hours after the episode, and returned to normal without treatment.

The eye condition was not altered for better or worse.

During the next 18 months the patient was gradually weaned from the steroid treatment and at the end of this time scratch tests were performed to $1 / 100,1 / 10$, and undiluted lyophilized alphachymotrypsin $(5000 \mu$ in $1 \mathrm{ml} .0 .9 \mathrm{NaCl})$. Apart from slight itching around the site of the undiluted chymotrypsin injection which occurred after half an hour and persisted for 15 minutes, there was no 
reaction. Intradermal tests with $0 \cdot 1 \mathrm{ml}$. of the same dilutions were then performed and there was still no redness, erythema, oedema, or irritation during the following 48 hours.

\section{Discussion}

The manufacturers of lyophilized alpha-chymotrypsin recognize that sensitivity reactions to this substance do occur, though rarely. They point out that, as this is a foreign protein which is being injected, sensitivity reactions are most likely to occur in individuals who have a previous history of allergy or after repeated injections of the drug. They suggest that such individuals should have a scratch or intradermal test with chymotrypsin before injections are begun. They also recommend that the usual remedies, such as adrenaline, H.P. Acthar gel, aminophylline, and antihistamines, should be at hand to deal with any untoward reactions.

In this particular case it was known that the patient had had a skin eruption during a course of P.A.S. and I.N.A.H. some 6 years previously, but he had no other allergic history, nor was there any family tendency to allergic reactions. Moreover he had previously had a full course of intramuscular trypsin with no ill effects and just before this episode a 2-week course of alpha-chymotrypsin, again without reaction. Although this had obviously constituted the "sensitizing dose", there was nothing to suggest that anything so dramatic or alarming in its severity was likely to occur.

In all, $2 \mathrm{ml}$. adrenaline $1 / 1,000$ was required to overcome this reaction, which was almost identical with the anaphylactic and anaphylactoid reactions to alphachymotrypsin described by Liebowitz and Ritter (1960) and by others, including Shimkin and Bierman (1949), MacLaren and Aladjem (1957), and Howell (1961). The moderately high dosage of steroids which the patient was having at the time appeared to have had absolutely no effect on the course or severity of the reaction. This dosage, $4 \mathrm{mg}$. betamethasone per day, would normally be expected to suppress or modify the sensitivity reaction.

Another interesting feature of this case is that the administration of intravenous aminophylline undoubtedly increased the breathlessness and bronchospasm to such an extent that the injection had to be discontinued after only $10 \mathrm{mg}$. had been given. There was no further increase in the breathlessness after the injection had been discontinued and it was rapidly relieved by a further subcutaneous injection of adrenaline $1 / 1,000$. Several reports have appeared of sudden death after intravenous injection of aminophylline, but all deaths have been in patients with cardiac disease and death has been from left ventricular failure (Merrill, 1943; Bresnick, Woodard, and Sageman, 1948). One report has appeared of a true sensitivity reaction to this drug, with skin eruptions and asthma (Tas and Weissberg, 1958), but the type of reaction described here does not appear to have been reported previously.

It is surprising that the patient, who nearly lost his life as a result of anaphylaxis following intramuscular injection of alpha-chymotrypsin, gave negative scratch and intradermal tests to the drug when they were performed 18 months later.

There are several possibilities. The skin tests may be a reliable indication of the danger of sensitivity reactions, but the patient may have become desensitized by his previous injections, or spontaneous desensitization may have occurred during the 18 months since the last injection. Alternatively, negative skin tests may not rule out the danger of anaphylaxis. It is not known whether skin tests would have been 
positive at the time of anaphylaxis nor, if they were negative, is it known whether they might not have become negative more rapidly than has the danger of anaphylaxis; it is not certain therefore that an anaphylactic reaction would not occur again if a further injection were given. Clearly, it is not possible to investigate this, but whatever the explanation of these recent negative skin tests, there must be some uncertainty about the complete safety of this drug even after skin-testing.

Intramuscular alpha-chymotrypsin is used at present for reducing severe oedema around the lids following trauma, and it has been suggested that it should be used routinely in all plastic procedures and after squint operations to reduce postoperative oedema (Fortier, 1961). This would seem most inadvisable because of the occasional but very severe reactions that may occur.

\section{Summary}

(1) An anaphylactic response to intramuscular injections of lyophilized alphachymotrypsin, given in an attempt to disperse recurrent vitreous haemorrhages in a case of Eales's disease, is described.

(2) The severity of the reaction did not appear to be affected by the moderately high doses of systemic steroids that the patient was receiving at the time.

(3) Subcutaneous adrenaline 1/1,000 produced an immediate response, but this dose had to be repeated before the patient's condition returned to normal.

(4) Intravenous aminophylline caused an increase in the bronchospasm. This has not been previously described.

(5) Skin tests 18 months after the anaphylactic reaction were negative, so that a negative skin test cannot be regarded as an adequate criterion of safety.

(6) Intramuscular alpha-chymotrypsin should be used with circumspection.

I should like to thank Mr. A. G. Cross for permission to publish the case, and Mr. Barrie Jones of Moorfields Eye Hospital, Dr. D. R. Laurence of University College Hospital, and Dr. J. Coulter of Armour Pharmaceutical Company, for their helpful discussions during the preparation of this report.

\section{REFERENCES}

Bresnick, E., Woodard, W. K., and Sageman, C. B. (1948). J. Amer. med. Ass., $136,397$.

Chandler, M. R., and Rosenthal, E. (1958). A.M.A. Arch. Ophthal., 59, 706.

FORTIER, E. G. (1961). Amer. J. Ophthal., 51, 196.

Hendley, C. D., Robbins, K. C., Dertinger, B., Clements, G. R., and Ercoli, N. (1956). Arch. int. Pharmacodyn., 106, 164.

Hopen, J. M. (1953). J. Philad. gen. Hosp., 4, 89. (1954). Amer. J. Ophthal., 38, 84.

and Campagna, F. N. (1954), J. Philad. gen. Hosp., 5, 20.

Howell, I. L. (1961). J. Amer. med. Ass., 175, 322.

INNERFIELD, I., and SCHWARTZ, A. (1953). Ibid., 152, 597.

- L, and ANGrist, A. A. (1952). Bull. N.Y. Acad. Med., 28, 537.

Liebowitz, D., and RITTER, H. (1960). J. Amer. med. Ass., 172, 159.

Maclaren, W. R., and Aladjem, F. (1957). J. Allergy, 28, 89.

MERCIER and JEZEGABEL (1960). Bull. Soc. ophtal. Fr., p. 307.

MerRill, G. A. (1943). J. Amer. med. Ass., 123, 1115.

MontAuFfier, R., DE LA BernARDIE, J., and CAMO, R. (1957). Bull. Soc. ophtal. Fr., p. 380.

PeCK, M. E. (1954). J. Amer. med. Ass., 154, 1260.

Perdriel, G. (1960). Bull. Soc. ophtal. Fr., p. 658.

PORTIER and RICHeT, C. (1902). C.R. Soc. Biol., Paris, 54, 170.

Shimkin, M. B., and Bierman, H. R. (1949). Proc. Soc. exp. Biol. (N.Y.), 71, 250.

TAS, J., and WEISSBERG, D. (1958). Acta allerg. (Kbh.), 12, 39.

TAYlor, A., OVerman, R. S., and Wright, I. S. (1954). J. Amer. med. Ass., $155,347$.

Wolstenholme, G. E. W., and O'ConNOR, C. M. (editors) (1956). "Ciba Foundation Symposium on Histamine," pp. 37 (J. H. Gaddum), 59 (W. D. M. Paton), 139 (H. O. Schild). Churchill, London. 